\title{
An Attention Economy Perspective on the Effectiveness of Incomplete Information
}

\author{
Nitza Geri \\ The Open University of Israel \\ Raanana, Israel \\ nitzage@openu.ac.il
}

Rebecca Schocken

Tel-Aviv University, Tel-Aviv

and The Open University of

Israel, Raanana, Israel

\author{
Seev Neumann \\ College of Management \\ Rishon Lezion, Israel \\ seevne@hdq.colman.ac.il
}

\author{
Yishai Tobin \\ Ben-Gurion University of the \\ Negev, Beer-Sheva, Israel
}

beckysc@openu.ac.il

yishai@bgu.ac.il

\begin{abstract}
This study suggests an attention economy perspective on incomplete information, asserting that people use partial information as basis for action, hence an effective information system should provide them just with the most useful partial information, and should avoid redundant information that wastes their limited attention resources. These assertions were empirically examined via simulation of a speech-reading process that measured the real and perceived value of two levels of partial speech-reading support. The findings indicate that additional partial information improved performance, but there was practically no significant difference between one and two signals support levels. High correlation was found between the different methods of evaluation, suggesting that perceived value may be used as substitute to real value measurement after considering the circumstances of the system involved. This research may provide important insights for designing information systems in general, as well as speech-reading support systems that will improve communication opport unities of hearing impaired people.
\end{abstract}

Keywords: attention economy, information economics, speech-reading, lip-reading, linguistics, human computer interaction, effectiveness of incomplete information, value of information

\section{Introduction}

Material published as part of this publication, either on-line or in print, is copyrighted by the Informing Science Institute. Permission to make digital or paper copy ofpart or all of these works for personal or classroomuse is granted without fee provided that the copies are not made or distributed for profit or commercial advantage AND that copies 1) bear this notice in full and 2) give the full citation on the first page. It is permissible to abstract these works so long as credit is given. To copy in all other cases orto republish or to post on a serveror to redistribute to lists requires specific permission and payment of a fee. Contact 0HPublisher@,InformingScience.org to request redistribution permission.
Human attention is considered as one of the scarcest resources in the information era (Davenport \& Beck, 2000, 2001;

Geri \& Gefen, 2007; Wiberg \& Whittaker, 2005). On one hand, computerized information systems increase information overload by enabling convenient information distribution and ample communication opport unities. On the other hand, cleverly designed information systems may provide users with 
useful information and help them cope with information overload by screening irrelevant messages.

The value of information has been one of the most central research issues ever since the early days of information systems (e.g., Dickson, Senn, \& Chervany, 1977). This paper adopts an attention economy perspective (Simon, 1957, 1971) and analyzes the value of incomplete information. Whereas in information economics contexts (McGuire \& Radner, 1986), partial information is usually regarded as inferior to complete information, and additional partial information is considered as improving the ability of the decision-maker to choose the correct course of action, this paper asserts that due to bounded rationality, additional partial information may not always improve the decision maker performance, and sometimes may even worsen it.

It should be emphasized that this research relates to additional partial information that is relevant and significant in the particular circumstances. It does not concern distracters, noise, and information design effects, such as flash (Hong, Thong, \& T am, 2004) or format (Eshet-Alkalai \& Geri, 2007).

A simulation of speech-reading has been used to empirically examine the real and perceived value of incomplete audit ory information. The participants had to understand a spoken message that they could not hear, and they were given one or two auditory signals. Each of these signals was supposed to reduce the ambiguity of the message. The findings indicate that additional partial information improved performance compared to unsupported speech-reading. However, no difference was found between one and two signals support levels (the concept of one and two signals support is explained in the Methodology Section). There were high correlations among the three methods of evaluation used in this study, and this suggests that perceived value may be used as a substitute for real value measurement, as defined in information economics, after considering the circumstances of the system involved.

The next section presents the theoretical background, which refers to the challenges of information evaluation as well as the challenges of speech-reading. The methodology section describes the experiment and the three performance evaluation measures, which were used to evaluate the success of the experiment participants in the simulated communication process. The results are followed by a discussion of the theoretical and practical implications of the findings, and conclusions.

\section{Theoretical Background}

\section{Challenges of Information Evaluation}

Information has no universal value. The value of information is relative and depends on the user, the timing and the circumstances (Ahituv, 1980; 1989; Ahituv, Neumann, \& Riley, 1994). Information economics relates to three main approaches to measuring the value of information: normative value, real value and perceived value (Ahituv, 1989):

- Normative value is theoretic and is based on mathematical models that define ex-ante, the best course of action.

- Real value is an empiric, quantitative and objective measure, which is based on the assumption that information affects performance. Therefore, it compares performance ex-post, with and without the information in order to measure its value.

- Perceived value is also referred to as subjective value (Raban, 2007; Raban \& Rafaeli, 2006), and is similar to the perceived usefulness concept of the Technology Acceptance Model

(TAM) (Davis, 1989; Davis, Bagozzi, \& Warshaw, 1989; Jeyaraj, Rottman, \& Lacity, 2006; 
Venkatesh, Morris, Davis, \& Davis, 2003). Perceived value is an empiric, quantitative subjective measure, which is based on human thoughts and perceptions. The premise is that people can identify the benefits they may gain from using the information, and transform these benefits either to monetary values or to ranking scales (Ahituv, 1989). Since people have to get the information or use the information system in order to evaluate its usefulness, the perceived value is usually measured ex-post. However, it can be measured ex-ante if the respondents are presented with a prototype, or if the respondents were exposed to similar systems in other organizations (Geri, 2006). Perceived value is the most common in empirical research literature, since it is much easier to measure.

However, studies that examined the real value of information, such as Lee, Clark and Tam (1999) who examined the effect of a continuous replenishment process system on the adopters' revenues, or Eshet-Alkalai and Geri (2007) who measured the impact of print and digital formats on critical reading performance, are rare. This review elaborates on two studies of real value that dealt with incomplete information, which is the focus of this study.

One of the early information system experiments, known as the Minnesota experiments (Dickson, et al., 1977), demonstrates that real value is not necessarily positively correlated with the perceived value of that information. In that particular experiment, two groups of participants in a business game were provided with production data. The first group received raw un-aggregated data, and the second group received just aggregated production data. Whereas the second group participants performed better and achieved higher profits, these participants were less confident of their performance compared with the first group members. That is, the incomplete information system had high real value, but was perceived by its users as less valuable.

These paradoxical results were practically used in the following years as basis for the design of decision-support systems(DSS) and executive information systems(EIS). DSS and EIS present the decision makers with aggregated processed information, but enable them to "drill down" and get the raw data behind the aggregated items. The presentation of few items improves the decision-makers' performance and the ability to check the details provides them with confidence that is essential for the use of such voluntary systems (Geri, 2006). Hence, the design of these systems follows the informing science principles of providing clients with information "in a form, format, and schedule that maximizes its effectiveness" (Cohen, 1999).

Ahituv, Igbaria and Sella (1998) measured the effect of incomplete information, as opposed to complete information, on the performance of air-force commanders, via simulations, and found that complete information generally improved performance, but field commanders did not improve their performance when presented with complete information undertime pressure.

According to the normative approach to information value, which is based on rational decisionmaking assumptions, theoretically, additional information has a nonnegative value (Ahituv \& Ronen, 1988). Hence, if cost is not considered, obtaining more information, such as a medical second opinion, should not worsen the decision-maker performance. However, bounded rationality (Simon, 1957, 1971), argues that the human cognition is limited in its ability to process information and therefore, people act upon partial information. For instance, when we use a search engine, such as Google, and get dozens of references, we will check only a few, and when we are satisfied with the results, we will disregard all the other references. Thus, since people use incomplete information as a basis for action, an effective information system should provide them with the most useful partial information. An attention economy perspective also implies that redundant information wastes the limited attention resources of people (Davenport \& Beck, 2000, 2001; Wiberg \& Whittaker, 2005). Hence, an effective information system should provide just the needed information. 
An effective information system in the context of this study is considered from the point of view of the client, as defined by Cohen (1999). Thus, any information that contributes to the client is useful. It should also be noted that the main costs of producing the information are fixed, that is planning, designing, building and implementing the system, whereas the marginal costs of providing the client with specific information are very low and practically negligible.

This study examines the effectiveness of additional incomplete information in the context of speech-reading and measures the real value, as well as the perceived value, of two levels of partial speech-reading support. The objective of the experiment is to find out whether the additional partial information improves speech-reading performance. The findings also enable a comparison of real and perceived value measurements and provide insights regarding the use of perceived value as a substitute for real value measurement.

\section{Challenges of Speech-Reading}

During speech-reading (also called lip reading), one lacks a large amount of information available to a person with unimpaired hearing. Utterances that sound different and enable a hearing person to make dist inctions look alike, and therefore the speech-reader is compelled to guess which word was uttered. Speech readers are unable to make acoustic dist inctions between different consonants, and they can detect only the visual characteristics of the utterances. For example, $\mathrm{f}$ and $\mathrm{v}$ look alike when produced orally (Vatikiotis-Bateson, Baily, \& Perrier, 2006). The lower lip touches the upperteeth, and one cannot tell which is $f$, and which is $v$. In the same manner, $p, b$, and $m$ are visually the same. The speaker's lips meet each other, and the results seem to be identical. Each group of consonants that look the same is called a viseme (visual phonemes), which is the combination of the concepts of phoneme, and the visual facial movements that are involved in the articulation of phonemes (Bernstein \& Auer, 1995). This research was conducted in Hebrew, which has about 20 consonants that a hearing person can distinguish between. However, in speech-reading these consonants are divided into just five dist inguishable visemes.

The issue of adding supporting visual signals, which enable distinction among the consonants of each viseme, is complex. On one hand, more signals reduce uncertainty and apparently should improve the chance of understanding the conveyed message. On the other hand, as the amount of signals increases, so is the load on the cognitive resources of the speech-reader, which makes it harder to process the information correctly and results in an increased probability of errors. Therefore, from an attention economy perspective (Simon, 1957, 1971), the challenge is to provide the hearing-impaired person with the least amount of supportive stimulations that would help distinguishing between the different consonants in each viseme, and enable a successful communication process.

\section{Methodology}

\section{The Experiment}

The research questions were examined by simulations that checked the value of various levels of speech-reading support. The purpose of the experiment was to investigate the optimal addition of supporting signals in each viseme that may improve speech-reading. The participants' comprehension level of the information conveyed during the experiment was used to measure the value of each one of the support settings. The success of the communication process was measured by three performance evaluation methods, which are further discussed below.

The support ing signals were based on a variation of the cued speech system (Cornett, 1967; Cornett, Beadles, \& Wilson, 1977). Unlike the cued speech system, the support suggested in this study is provided just to some of the consonants in each viseme and not to all of them, due to the 
limited human cognitive ability to process information. The rationale for this approach is statistical. The objective is to always assign the cue label to the consonant most frequently used within the viseme (Schocken, 2008). For instance, in the viseme bmp, the $\mathrm{m}$ is the most frequently used in Hebrew, and it will get the first cue label. Thus, the speech-reader will be left with a choice between $b$, and $\mathrm{p}$. In this approach, statistics proves that uncertainty will be reduced to a minimum. In case we had used the cue label in order to make a distinction between $b$, and p, statistics shows that the speech-reader would be faced with higher level of uncertainty and a more frustrating guess (Schocken, 2008; Schocken Topaz, 1999). If the level of support is raised to two cues, the second cue will be affixed to the consonants that rank second in terms of frequency within the viseme, and so on. The experiment included two levels of support, one signal for the most frequent consonant in each viseme, and two signals for thetwo most frequent consonants in each viseme.

\section{The Participants}

The use of visual stimulations to support speech-reading requires lengthy training (Nicholls \& Ling, 1982). Moreover, it is difficult to perform such simulations with hearing impaired people since some of them are very proficient in speech-reading and their performance will be high, regardless of the amount and nature of additional supporting auditory or other sort of information. Hence, the experiment was conducted with hearing people who were provided with supporting auditory stimulations, instead of visual ones. This choice also ensured a unified level of hearing abilities, which would have been hard to control with hearing impaired participants.

The participants were 79 people who volunteered to take part in the experiment. All of them had normal hearing and normal sight (or their sight was corrected by eyeglasses). They all belonged to the age group of young adults, between 19 and 41 years old, in order to control age-related changes, which affect cognitive and linguistic abilities (Bergman, 1980).

The main fact ors that influence speech-reading are: level of hearing (Erber, 1982), sight (Jeffers \& Barley, 1978), age (Bergman, 1980), ability to synthesize the cues (Jeffers \& Barley, 1978; Golan, 1995), psychological and cultural aspects (Sekiyama, 1997; Sekiyama \& Tohkura, 1993), as well as level of proficiency in the language (Boothroyd, 1988).

The hearing, age and language proficiency were controlled beforehand during the selection of the volunteers. The sight factor is partially controlled since the specific sight aspects such as focus abilities were not checked. Personality factors as the ability to synthesize the cues, as well as psychological and cultural aspects, were not controlled.

\section{The Experiment Design and Procedure}

There are many diverse factors, which affect the success of a communication process. Therefore, in order to neutralize or reduce the impact of these factors, a simple and clear communication task was defined. The participants were asked to view a woman in a video recording. The woman announcer sat in front of the camera and conveyed simple sentences in Hebrew. During the experiment, the participants were asked to write down the sentences. The written reconstruction of the conveyed sentences represents the messages as they were understood by the participants and this data was used to evaluate the success of the communication process.

The experiment was designed as a simulation, which imitates the uncertainty situation that is equivalent to speech reading, and the supporting data were conveyed to the participants through their hearing channel. The soundtrack of the video has been electronically processed, and segments, which relate to certain phonemes, were erased according to the different simulation situations. For instance, in order to simulate speech-reading alone, the whole soundtrack has been erased, and in order to simulate one signal support level, only the most frequent consonant in each 
viseme was left in the soundtrack of the video. The procedure of audit ory stimulation has been selected in orderto avoid the need to train the participants and to prevent additional disruption, which may result from different levels of participants' proficiency.

The participants were divided into three groups of 25-28 people, and each group performed a different simulation. The sentences that were used as test data are based on CUNY - topic related sentences (Boothroyd, Hnath-Chisolm, Hanin, \& Kishon-Rabin, 1988), which are lists of simple sentences that are frequently used in speech perception research. There were six lists consisting of 12 sentences, and each simulation set included all those lists in different auditory stimulation conditions.

The participants were given blank forms, arranged as tables that included the topic of each sentence, a blank space for filling-in the sentence, and a scale for evaluating the participant's confidence in understanding the sentence. The topic stated before each sentence provides the participants with the context (e.g., family, work, a restaurant), in order to simulate real life situations. Each sentence was broadcasted once, the experiment supervisor showed the video, and stopped at the end of each sentence in order to give the participants time to write down the sentence. There was no time constraint and the participants were asked to guess single words when they were unable to reconstruct a complete meaningful sentence.

Since the dictation task, which lasts approximately half an hour, is tiresome and requires concentration, a control group has performed the experiment with complete auditory information (i.e., no parts of the soundtrack were erased). The performance of the control group was almost perfect, therefore, it indicates that the performance of the participants was not influenced by the nat ure of the task and they were able to cope with it.

\section{Performance Evaluation Measures}

The participants' level of success in understanding the received messages was evaluated in three different methods, two of them represent the real value of information and the third is a subjective measure, which stands for perceived value.

\section{Rate of identified words}

The performance of the participant was given a score between zero and one, which represents the rate of words that were correctly identified. Each content word was assigned two points, and each preposition (e.g., in, on, the) was assigned one point, because prepositions are connected to a content word. A full score was given only when the participant was completely accurate in identifying the word. This is a quant it at ive measure of the communication process success. The method is objective, and could even be automated. Nevertheless, a person may identify $90 \%$ of the words and yet would not understand the meaning of the sentence at all.

\section{Objective judge}

An Objective person (hereafter referred to as judge) has read the texts and evaluated to which extent the participant understood the messages transferred by the announcer in the video recording, on the following scale:

1. A wrong message has been comprehended.

2. No message has been comprehended.

3. It is unclear whether the message has been comprehended.

4. A partial message has been comprehended, but most of the meaning has been conveyed.

5. A full message has been comprehended. 
Arguably, this is supposed to be a better evaluation than the rate of the identified words, since a person may correctly identify a large proportion of the words, but still get the wrong meaning of the message.

\section{Selfevaluation}

The participants were asked to rate on a scale of 1 to 5 their level of confidence in understanding the message:

1. I did not understand the message.

2. I am not sure I understood the message.

3. I do not know whether I understood the message.

4. I think I understood most of the message.

5. I am sure I understood the message.

This measure is subjective and represents the perceived value of information. People may think that they understood the message, when in reality they misunderstood it completely. Nevertheless, the perceived value is the most common method of evaluation because it is simpler, and since usually high perceived value, or perceived usefulness (Davis, 1989), influences behavioral intention to use an information system.

\section{Results}

The statistical analyses were performed with SP SS version 14.0. Demographic characteristics of the 79 simulation participants are presented in Table 1. The sample was homogeneous and no gender or education differences were found in the analysis, except for significant positive influence of number of years of education just on one measurement, the word count score of the onesignal simulation. Age did not affect speech-reading performance, and the self-evaluations in the partial information states, but age was significantly correlated with the two real value measures hence suggesting that older participants performed better than younger ones in incomplete auditory information states. The results of the gender, age and education correlations with the participants' performance are presented in the Appendix.

The results of the control simulation with complete auditory information practically showed that the participants had full comprehension of the messages, and therefore, the performance of the participants was not influenced by the tiresome nat ure of the task. It also confirmed that that the messages were comprehendible.

\begin{tabular}{|l|l|c|c|c|}
\hline \multicolumn{4}{|c|}{ Table 1. Demographic characte ristics of the simul ation participants } \\
\hline \multirow{2}{*}{ Gender } & Men & Women & Total \\
\cline { 3 - 5 } & $42(53 \%)$ & $37(47 \%)$ & 79 \\
\hline \multirow{4}{*}{ Age } & Average & 27.6 & 27.5 & 27.5 \\
\cline { 2 - 5 } & SD & 6.6 & 6.8 & 6.7 \\
\cline { 2 - 5 } & Range & $21-41$ & $19-41$ & $19-41$ \\
\hline \multirow{2}{*}{$\begin{array}{l}\text { Education } \\
(Y) a r s)\end{array}$} & Average & 14.8 & 14.8 & 14.8 \\
\cline { 2 - 5 } & SD & 2.7 & 3.2 & 2.9 \\
\cline { 2 - 5 } & Range & $10-22$ & $12-24$ & $10-24$ \\
\hline
\end{tabular}


The average performance evaluations of the participants in each of the four simulations are presented in Table 2, according to the three methods. The speech-reading condition, with no auditory information has been carried out by 25 people, and another group of 26 performed the control simulation with complete auditory information. A third group of 28 participants carried out the two simulations with the incomplete auditory information.

\begin{tabular}{|l|c|c|c|c|c|c|c|}
\hline \multicolumn{7}{|c|}{ Table 2. Performance measu res of su pporte d speech-re ading } \\
\hline \multicolumn{2}{|c|}{} & \multicolumn{5}{c|}{ Real value } & \multicolumn{2}{c|}{$\begin{array}{c}\text { Perceived } \\
\text { value }\end{array}$} \\
\cline { 2 - 8 } & \multicolumn{2}{|c|}{$\begin{array}{c}\text { Quantitative } \\
\text { Score }\end{array}$} & $\begin{array}{c}\text { O bjective } \\
\text { Ju dge }\end{array}$ & \multicolumn{2}{c|}{$\begin{array}{c}\text { Self- } \\
\text { Evaluation }\end{array}$} \\
\hline Simulation & $\mathbf{n}$ & Ave rage & SD & Average & SD & Ave rage & SD \\
\hline Speech-reading & 25 & 0.31 & 0.18 & 1.72 & 0.59 & 2.22 & 0.82 \\
\hline One signal & 28 & 0.58 & 0.16 & 2.73 & 0.69 & 3.17 & 0.72 \\
\hline Two signals & 28 & 0.65 & 0.14 & 2.54 & 0.68 & 3.22 & 0.66 \\
\hline $\begin{array}{l}\text { Hear: Complete Auditory } \\
\text { Information (control) }\end{array}$ & 26 & 1.00 & 0.01 & 4.96 & 0.08 & 4.95 & 0.10 \\
\hline
\end{tabular}

Figure 1 presents the average evaluations according to the three methods. The quant it at ive score has been normalized to a scale of 1 to 5 for easier visual comparison with the other two measures.

It is evident in both Table 2 and Figure 1 that partial auditory information improves the performance compared to speech reading alone. However, it is unclear whether two signals are better than one. Table 3 presents the results of paired samples t-tests, which compare the results of the one signal simulation with those of the two signals simulation. From the subjective point of view of the participants, there is no significant difference between one and two signals (pair 3, $t=-.724$, insignificant). However, the quant it at ive score was significantly better with two signals (pair 1 , $\mathrm{t}=-4.426$ ). Contrarily, according to the judge evaluations, one signal was significantly better than

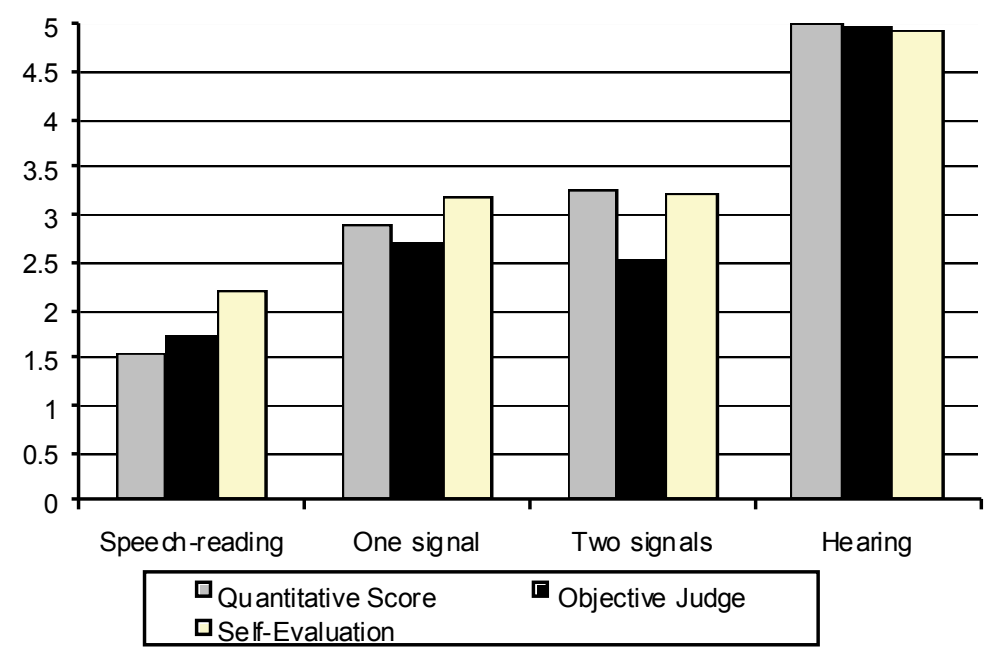

Figure 1: Performan ce measures of supported spee ch-re ading 
two signals (pair2, $t=2.189$ ). Nevertheless, the differences in the results were minor, hence practically it can be concluded that there are no performance differences between one and two signals.

\begin{tabular}{|c|c|c|c|c|c|c|c|c|c|}
\hline & & \multicolumn{5}{|c|}{ Paired Diffe ren ces } & \multirow{3}{*}{$\mathbf{t}$} & \multirow{3}{*}{$\mathrm{df}$} & \multirow{3}{*}{$\begin{array}{c}\text { Sig. } \\
\text { (2-tailed) }\end{array}$} \\
\hline & & \multirow[t]{2}{*}{ Mean } & \multirow[t]{2}{*}{ SD } & \multirow[t]{2}{*}{$\begin{array}{l}\text { Std. Error } \\
\text { Mean }\end{array}$} & \multicolumn{2}{|c|}{$\begin{array}{l}95 \% \text { Confidence } \\
\text { Interval ofthe } \\
\text { Difference }\end{array}$} & & & \\
\hline & & & & & Lower & Upper & & & \\
\hline Pair 1 & $\begin{array}{l}\text { One Signal-Score - } \\
\text { Two signals-Score }\end{array}$ & -.0709 & .085 & .0160 & -.104 & -.038 & -4.426 & 27 & .000 \\
\hline Pair 2 & $\begin{array}{l}\text { One Signal-Judge - } \\
\text { Two signals-Judge } \\
\end{array}$ & .197 & .477 & .0901 & .012 & .382 & 2.189 & 27 & .037 \\
\hline Pair 3 & $\begin{array}{l}\text { One Signal-Self- } \\
\text { Two signals-Self }\end{array}$ & -.051 & .369 & .0698 & -.194 & .093 & -.724 & 27 & .476 \\
\hline
\end{tabular}

Another observation, which is evident from the data, is the similarity between the evaluations in all the three methods. Table 4 presents Pearson correlations between the methods regarding the evaluations of the speech-reading, one signal and two signal simulations. The three evaluations of the complete hearing information are practically the same, so their correlations were not checked. As shown in Table 4, all the correlations were significant with values from 0.776 to 0.931 , indicating high correlations between the three methods of evaluation.

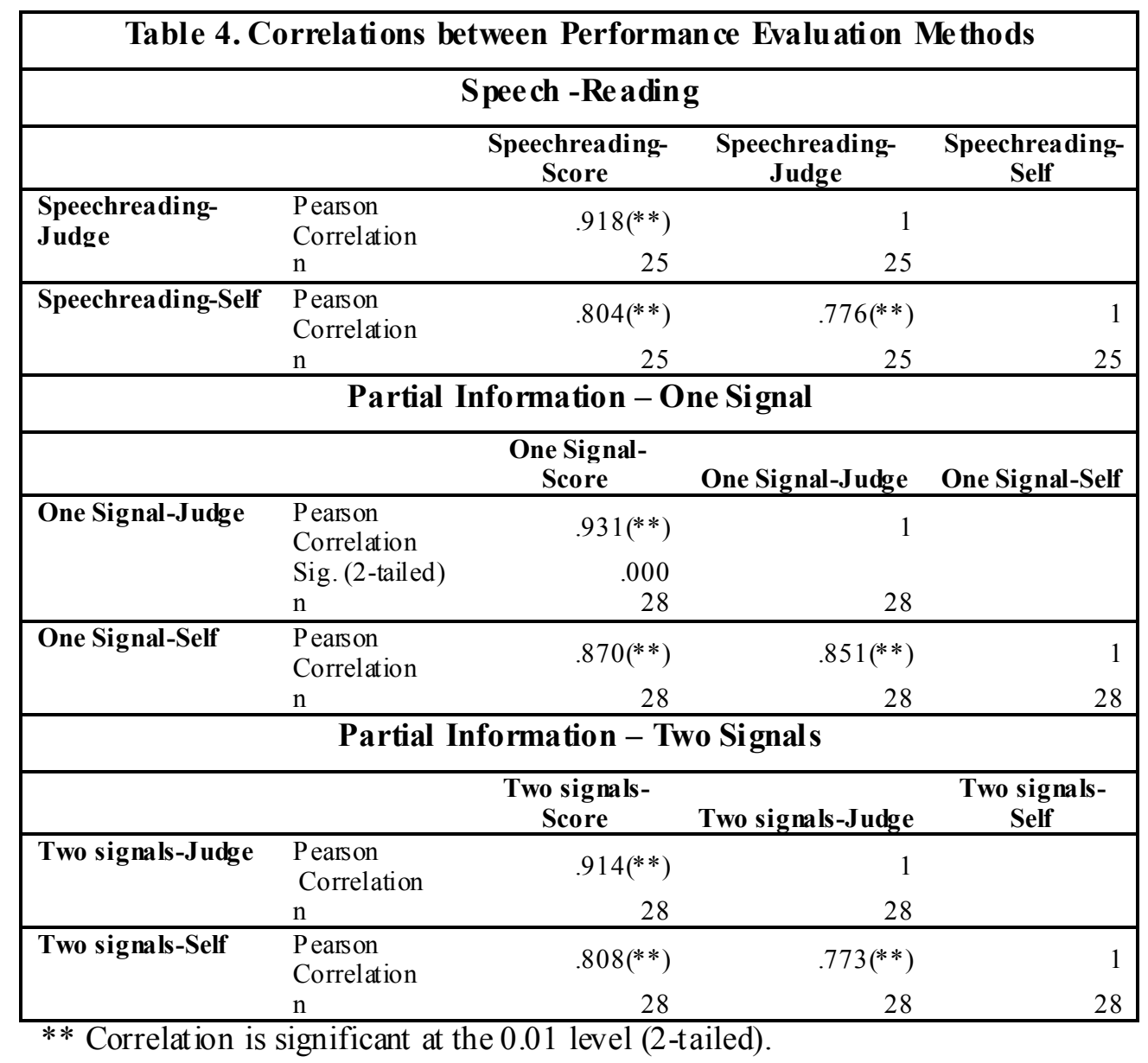




\section{Discussion}

\section{Theoretical Implications, Limitations and Further Research}

This study probed the issue of incomplete information effectiveness by empirically examining the impact of supportive incomplete auditory information on speech-reading performance. The findings indicate that the additional partial information improved performance, but there was practically no significant difference between one and two signals for each viseme. This study employed an information economics approach and regarded the processes and factors that affect speechreading performance as a "black box". Apart of the attention economy reasoning (Simon, 1957, 1971; Davenport \& Beck, 2000, 2001; Geri \& Gefen, 2007; Hong et al., 2004; Wiberg \& Whittaker, 2005), it did not explain why the additional partial information (i.e., two signals) did not improve the participants' performance. Further research based on perspectives from other disciplines, such as cognitive psychology and psycholinguistics, may shed light on this issue, and provide explanations for this phenomenon.

No education differences were found in the analysis, except for significant positive influence of number of years of education on the word count score of the one-signal simulation. This difference may be incidental, since education did not influence the other 11 measures shown in the Appendix. However, the sample was homogenous and the participants had between 10 to 24 years of education, therefore more empirical studies with larger and less homogeneous samples are required to investigate this matter.

The results regarding the influence of age on the participants' performance (presented in the Appendix) call for further research. On one hand, age did not affect speech-reading performance, and the self-evaluations in the partial information states, but on the other hand, age was significantly correlated with the two real value measures implying that older participants performed betterthan younger ones in incomplete auditory information states. This study does not provide an explanation for this influence, and it would be worthwhile to investigate whether this phenomenon is unique to incomplete auditory information or it relates to other sit uations of incomplete information as well.

The provided partial information was based on a variation of the cued speech system (Cornett, 1967; Cornett et al., 1977). Other methods, such as phonology as human behavior (Diver, 1979; Tobin, 1997, 2007), may assign different stimulations, which may lead to speech-reading performance that is betterthan the results obtained with the cued speech method. Hence, future research should examine the effectiveness of other methods, as well as whether the second signal for each viseme is redundant, regardless of the logic behind the assignment of the cues.

This study compared real and perceived values of information, and contributed empirical evidence to the body of knowledge in this issue, which has been rarely studied in information system contexts. The findings indicate high correlation between the different methods of evaluation. Nevertheless, mixed results were reported in prior research (e.g., Dickson et al., 1977), hence further empirical study is required.

\section{Practical Implications}

The experiment described in this paper is part of a comprehensive research that aims to find ways to support speech-reading by hearing impaired people and to suggest practical tools to evaluate the contribution of such support systems. Speech recognition technologies cannot provide adequate support by translating speech to text due to the unsolved challenge of computer understanding of common knowledge (Ein-Dor, 1999). On the other hand, innovative information and communication technologies offer exciting solutions for conducting aural electronic communication, 
which enable various methods of conversation. Hence, an information system, which enables a hearing impaired person to see the person who talks, and adds a few supporting signals, may greatly improve their performance. Too many signals may pose a cognitive overload on hearing impaired people. Therefore, the results of this study, which suggest that support of one signal for each viseme can considerably improve speech-reading and that practically, one signal is enough, may help further develop such systems, and offer the hard of hearing community a new channel of communication with the hearing world.

The findings regarding the comparison of real value and perceived value measures present another practical contribution of this study, since they support the use of perceived value evaluation, obtained from the users as a substitute to measurement of the real value of information systems, which is much harder to measure. However, due to contrary findings by other researchers (Dickson et al., 1977), as well as ample real world examples, such use should be carefully considered according to the specific circumstances of the measured in formation system.

\section{Conclusion}

This study examined the effectiveness of incomplete information from an attention economy perspective. It asserted that since people rely on incomplete information as a basis for action, due to bounded rationality, an effective information system should provide users with the most useful partial information, and it should provide just the needed information, because redundant information wastes the limited attention resources of people.

These assertions were empirically examined regarding a speech-reading process, which is inherently complex due to the high level of uncertainty involved. The supportive partial information, based on just one signal for the most common consonant in each viseme, greatly improved the participants' speech-reading performance. A normal communication process, which involves hearing people, includes ample redundant information, which does not impair comprehension of the conveyed messages. However, speech-reading is a more demanding cognitive process, and as a paraphrase on Simon (1971), it may be suggested that a wealth of partial information in a communication process creates a poverty of comprehension. Hence, this research may provide important insights for designing information systems in general, as well as speech-reading support systems that will improve the communication opportunities of hearing impaired people.

\section{References}

Ahituv, N. (1980). A systematic approach toward assessing the value of an in form ation system. MIS Quarterly, 4(4), 61-75.

Ahituv, N. (1989). Assessing the value of inform ation: Problems and approaches. Proceedings of the 10th Annual International Conference on Information Systems, Boston, MA (December 1989), 315-325.

Ahituv, N., Igbaria, M., \& Sella, A. (1998). The effects of time pressure and completen ess of in formation on decision-making. Journal of Management Information Systems, 15(2), 153-172.

Ahituv, N., Neumann, S., \& Riley, H. N. (1994). Principles of information systems for management. Dubuque, IA: Wm C. Brown Communications.

Ahituv, N., \& Ronen, B., (1988). Orthogonal information structures - A model to evaluate the information provided by a second opinion. Decision Sciences, 19(2), 255-268.

Bergman, M. (1980). Aging and the perception of speech. Baltimore, MD: University Park Press.

Bernstein, L. E., \& Auer, E. T. Jr. (1995). Word recognition in speechreading. In D. G. Stork \& M. E. Hennecke (Eds.), Speechreading by humans and machines: Models, systems and applications (pp.17-26). Berlin: Springer-Verlag.

Boothroyd, A. (1988). Linguistic factors in speechreading. Volta Review, 90, 77-87. 
Boothroyd, A., Hnath-Chisolm, T., Hanin, L., \& Kishon-Rabin, L. (1988). Voice fundament al frequency as an auditory supplement to the speechreading of sentences. Ear and Hearing, 9, 306-312.

Cohen, E. (1999). Reconceptualizing information systems as a field of the transdiscipline informing science: From ugly duckling to swan, Journal of Computing and Information Technology, 7(3), 213-219.

Cornett, R. O. (1967). Cued speech. American Annals of the Deaf, 112, 3-13.

Cornett, R. O., Beadles, R., \& Wilson, B. (1977). Automatic cued speech. Proceeding of Research Conference on Speech-Processing Aids for the Deaf. Washington, DC: Gallaudet College, pp. 224-239.

Davenport, T. H., \& Beck, J. C. (2000). Getting the attention you need. Harvard Business Review, 78(5), 118-126.

Davenport, T. H., \& Beck, J. C. (2001). The attention economy: Understanding the new currency of businesses. Boston, MA: Harvard Business School Press.

Davis, F. D. (1989). Perceived usefuln ess, perceived ease of use, and user acceptan ce of information technology. MIS Quarterly, 13(3), 318-340.

Davis, F. D., Bagozzi, R. P., \& Warshaw, P. R. (1989). User acceptance of computer technology: A comparison of two theoretical models. Management Science, 35(8), 982-1004.

Diver, W. (1979). Phonology as human behavior. In D. Aaronson \& P. Reiber (Eds.), Psycholinguistic research: Implications and applications (pp. 161-186). Hillsdale, NJ: Lawrence Erlbaum.

Dickson, G. W., Senn, J. A., \& Chervany, N. L. (1977). Research in management information systems: The Minnesota experiments. Management Science, 23(9), 913-923.

Ein-Dor, P. (1999) Artificial intelligence: A short history and the next forty years. In K. E. Kendall (Ed.), Emerging information technologies: Improving decisions, cooperation, and infrastructure (pp.117140). Thousand Oaks, CA: Sage.

Erber, N. P. (1982). Auditory training. Washington, DC: Bell Association for the Deaf.

Eshet-Alkalai, Y., \& Geri, N. (2007). Does the medium affect the message? The influence of text representation format on critical thinking. Human Systems Management, 26(4), 269-279.

Geri, N. (2006). Selected topics in economics of information goods. Raanana, Israel: Open University Press (Hebrew).

Geri, N., \& Gefen, D. (2007). Is there a value paradox of e-learning in MBA programs? Issues in Informing Science and Information Technology, 4(1), 163-174. Available at http://proceedings.informingscience. org/InSITE2007/IISIT v4p163-174Geri322.pdf

Golan, L. (1995). Reading between the lips - A totally deaf man makes it in the mainstream. Chicago, IL: Bonus Books.

Hong, W., Thong, J. Y. L., \& Tam, K. Y. (2004). Does animation attract online users' attention? The effects of flash on information search performance and perceptions. Information Systems Research, 15(1), 60-86.

Jeffers, J., \& Barley, M. (1978). Speechreading (Lipreading) (6 ${ }^{\text {th }}$ ed.). Springfield, IL: Charles C Thomas.

Jeyaraj, A., Rottman, J. W., \& Lacity, M. C. (2006). A review of the predictors, linkages, and biases in IT innovation adoption research. Journal of Information Technology, 21(1), 1-23.

Lee, H. G., Clark, T., \& Tam, K. Y. (1999). Research report: Can EDI benefit adopters? Information Systems Research, 10(2), 186-195.

McGuire, C. B., \& Radner, R. (Eds.). (1986). Decision and organization (2 ${ }^{\text {nd }}$ ed.). Minneapolis, MN: University of Minnesota Press.

Nicholls, G., \& Ling, D. (1982). Cued speech and the reception of spoken language. Journal of Speech and Hearing Research, 25, 262-269. 
Raban, D. R, (2007). User-centered evaluation of in formation: A research challenge. Internet Research, 17(3), 306-322.

Raban, D. R., \& Rafaeli, S. (2006). The effect of source nature and status on the subjective value of information. Journal of the American Society for Information Science and Technology, 57(3), 321-329.

Schocken, R. (2008). Characterization and evaluation of speech-reading support systems for hard-ofhearing people. Unpublished doctoral dissertation, Tel-Aviv University, Tel-Aviv, Israel (Hebrew).

Schocken Topaz, R. (1999). A speech-reading support system for hard-of-hearing people. Unpublished master's thesis, Tel-Aviv University, Tel-Aviv, Israel (Hebrew).

Sekiyama, K. (1997). Cultural and linguistic factors in audiovisual speech processing: The McGurk effect in Chinese subjects. Perception \& Psychophysics, 59(1), 73-80.

Sekiyama, K., \& Tohkura, Y. (1993). Inter-language differences in the influence of visual cues in speech perception. Journal of Phonetics, 21, 427-444.

Simon, H. A. (1957). Models of man: Social and rational. New York: John Wiley and Sons.

Simon, H. A. (1971). Designing organizations for an information-rich world. In M. Greenberg er (Ed.), Computers, communications and the public interest (pp.40-41). Baltimore, MD: Johns Hopkins Press.

Tobin, Y. (1997). Phonology as human behavior: Theoretical implications and clinical applications. Durham, NC: Duke University Press.

Tobin, Y. (2007). Comparing and contrasting natural phonology with the theory of phonology as human behavior. Proceedings of 16th International Congress of Phonetics Sciences (ICPhS XVI), Saarbrücken, Germany, August 6-10, 2007, 103-106. Retrieved February 22, 2008 from http://www.icphs2007.de/conference/Papers/1753/1753.pdf

Vatikiotis-Bateson, E., Baily, G., \& Perrier, P. (Eds.) (2006). Audio-visual speech perception. Cambridge, MA: MIT Press.

Venkatesh, V., Morris, G.M., Davis, G.B., \& Davis, F.D. (2003). User acceptance of in formation technology: Toward a unified view. MIS Quarterly, 27(3), 425-478.

Wiberg, M., \& Whittaker, S. (2005). Managing availability: Supporting lightweight negotiations to handle interruptions. ACM Transactions on Computer-Human Interaction (TOCHI), 12(4), 356-387. 


\section{Appendix. Gender, Age and Education Correlations with the Participants' Performance}

\begin{tabular}{|c|c|c|c|c|}
\hline & & Gender & Age & Education \\
\hline \multirow[t]{3}{*}{ Age } & Pearson Correlation & -.011 & 1 & \\
\hline & Sig. (2-tailed) & .923 & & \\
\hline & $\mathrm{n}$ & 79 & 79 & \\
\hline \multirow[t]{3}{*}{ Education } & Pearson Correlation & .009 & $.626(* *)$ & 1 \\
\hline & Sig. (2-tailed) & .937 & .000 & \\
\hline & $\mathrm{n}$ & 79 & 79 & 79 \\
\hline \multirow[t]{3}{*}{ Speechreading-Score } & Pearson Correlation & .347 & .177 & .312 \\
\hline & Sig. (2-tailed) & .089 & .396 & .130 \\
\hline & $\mathrm{n}$ & 25 & 25 & 25 \\
\hline \multirow{3}{*}{ Speechreading-Judge } & Pearson Correlation & 291 & .267 & .301 \\
\hline & Sig. (2-tailed) & .158 & .197 & .144 \\
\hline & $\mathrm{n}$ & 25 & 25 & 25 \\
\hline \multirow{3}{*}{ Speechreading-Self } & Pearson Correlation & .243 & -.090 & .088 \\
\hline & Sig. (2-tailed) & .241 & .667 & .677 \\
\hline & $\mathrm{n}$ & 25 & 25 & 25 \\
\hline \multirow[t]{3}{*}{ One Signal-Score } & Pearson Correlation & .263 & $.516(* *)$ & $.393(*)$ \\
\hline & Sig. (2-tailed) & .177 & .005 & .039 \\
\hline & $\mathrm{n}$ & 28 & 28 & 28 \\
\hline \multirow[t]{3}{*}{ One Signal-Judge } & Pearson Correlation & .315 & $.498(* *)$ & .362 \\
\hline & Sig. (2-tailed) & .102 & .007 & .059 \\
\hline & $\mathrm{n}$ & 28 & 28 & 28 \\
\hline \multirow[t]{3}{*}{ One Signal-Self } & Pearson Correlation & .225 & .359 & .215 \\
\hline & Sig. (2-tailed) & .249 & .061 & .271 \\
\hline & $\mathrm{n}$ & 28 & 28 & 28 \\
\hline \multirow[t]{3}{*}{ Two signals-Score } & Pearson Correlation & .183 & $.504(* *)$ & .352 \\
\hline & Sig. (2-tailed) & .352 & .006 & .066 \\
\hline & $\mathrm{n}$ & 28 & 28 & 28 \\
\hline \multirow[t]{3}{*}{ Two signals-Judge } & Pearson Correlation & .229 & $.380(*)$ & .275 \\
\hline & Sig. (2-tailed) & .241 & .046 & .157 \\
\hline & $\mathrm{n}$ & 28 & 28 & 28 \\
\hline \multirow[t]{3}{*}{ Two signals-Self } & Pearson Correlation & .203 & .310 & .211 \\
\hline & Sig. (2-tailed) & .299 & .109 & .281 \\
\hline & $\mathrm{n}$ & 28 & 28 & 28 \\
\hline \multirow[t]{3}{*}{ Hear-Score } & Pearson Correlation & -.061 & .015 & .126 \\
\hline & Sig. (2-tailed) & .767 & .942 & .540 \\
\hline & $\mathrm{n}$ & 26 & 26 & 26 \\
\hline \multirow[t]{3}{*}{ Hear-Judge } & Pearson Correlation & -.163 & -.075 & .014 \\
\hline & Sig. (2-tailed) & .427 & .717 & .947 \\
\hline & $\mathrm{n}$ & 26 & 26 & 26 \\
\hline \multirow[t]{3}{*}{ Hear-Self } & Pearson Correlation & -.255 & .271 & .232 \\
\hline & Sig. (2-tailed) & .209 & .181 & .254 \\
\hline & $\mathrm{n}$ & 26 & 26 & 26 \\
\hline
\end{tabular}

* Correlation is significant at the 0.05 level (2-tailed).

** Correlation is significant at the 0.01 level (2-tailed). 


\section{Biographies}

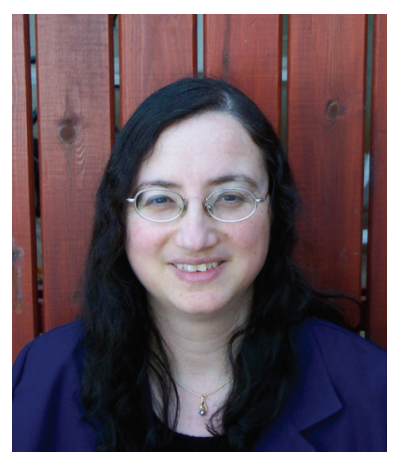

Nitza Geri is Head of Undergraduate Management Studies at the Department of Management and Economics at The Open University of Israel and a member of the Chais Research Center for the Int egration of Technology in Education. She holds a B.A. in Accounting and Economics, an M.Sc. in Management Sciences and a Ph.D. in Technology and Information Systems Management from Tel-Aviv University. Nitza is a CP A (Israel) and prior to her academic career she had over 12 years of business experience. Her research interests and publications focus on various aspects of the value of information, and information systems adoption and implementation, which include strategic information systems, e-business, value creation and the Theory of Constraints, managerial aspects of e-learning systems adoption and use.

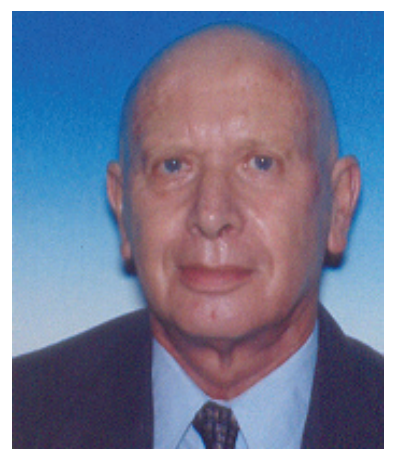

Seev Neumann is currently the President of the College of Management, Israel. He is a Professor Emeritus at Tel Aviv University and was the Mexico Professor of MIS at the Recanati Graduate School of Business Administration. He received his BS from the Hebrew University of Jerusalem and his MBA and Ph.D. (1967) from the University of California. Seev has published nine books and more than forty refereed articles. His research interests are information systems policy, information systems economics and information systems security. Since 1985, Seev has held a joint appointment at the School of Information Science, Claremont Graduate University. He has served as Dean of the Recanati Graduate School of Business Administration in 1973-1978 and in 1985-1989. He has held visiting positions at the University of Illinois, the University of California, Sasin Graduate School of business Administration, Bangkok, and the University of Cape Town.

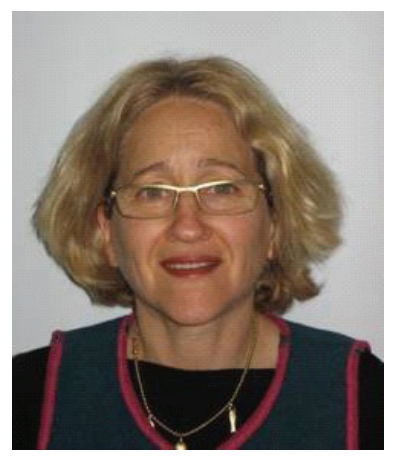

Becky Schocken is a course coordinator for the Open University of Israel at the MBA program; she also chairs the board of The Organization of Hard of Hearing and Deafened People in Israel. She is a doctoral student at the Faculty of Management, Tel-Aviv University. Her doctoral research focuses on characterizing and evaluating speechreading systems for the hearing impaired.

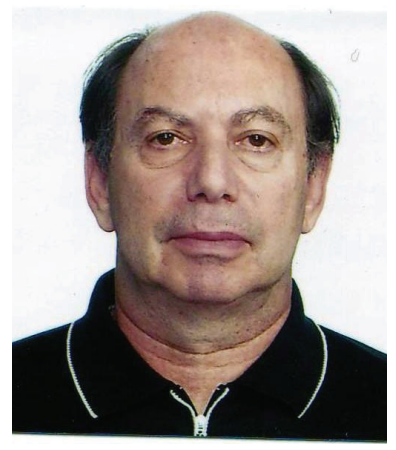

Yish ai Tobin is a professor in the Departments of Foreign Literatures $\&$ Linguistics and the Department of Behavioral Sciences at the BenGurion University of the Negev. He is the author and editor of 15 books and over 185 articles in the fields of developmental and clinical phonetics and phonology, discourse and text analysis, and semiotics. His research reflects a cognitive and functional approach to language as a system of signs used by human beings to communicate. 